\title{
Research
}

\section{Acceptability of a primary care-based opioid and pain review service:}

\author{
a mixed-methods evaluation in England
}

\begin{abstract}
Background

Primary care opioid prescribing to treat chronic non-cancer pain (CNCP) has progressively increased despite a lack of evidence for longterm safety and effectiveness. Developing primary care interventions to reduce opioid dependence in patients with CNCP is a public health priority.
\end{abstract}

\section{Aim}

To report the acceptability of the South Gloucestershire pain and opioid review service for patients with CNCP, which aimed to help patients understand their relationship with prescribed opioids and support non-drugbased pain management strategies.

\section{Design and setting}

A mixed-methods evaluation was performed on the service, which was based in two GP practices in South Gloucestershire, England, and delivered by project workers.

\section{Method}

Descriptive data were collected on deliveredwithin-service and community-based interventions. Twenty-five semi-structured interviews ( $n=18$ patients, $n=7$ service providers) explored experiences of the service.

\section{Results}

The enrolment process, person-centred primary care-based delivery, and service content focused on psychological issues underlying $\mathrm{CNCP}$ were found to be acceptable to patients and service providers. Patients welcomed having time to discuss their pain, its management, and related psychological issues. Maintaining a long-term approach was desired as CNCP is a complex issue that takes time to address. GPs recommended that funding was needed to ensure they have dedicated time to support a similar service and to ensure that project workers received adequate clinical supervision.

\section{Conclusion}

This service model was acceptable and may be a useful means to manage patients with CNCP who develop opioid dependence after longterm use of opioids. A randomised controlled trial is needed to formally test the effectiveness of the service.

\section{Keywords}

chronic pain; health promotion; opioid-related disorders; pain; pain management; primary health care.

\section{INTRODUCTION}

Primary care opioid prescribing ${ }^{1-4}$ to treat chronic non-cancer pain (CNCP) $)^{5-11}$ has progressively increased over the last 20 years. ${ }^{5-14}$ Prescribing varies geographically with larger practice list size, rural, and higher deprivation areas associated with high-dose opioid prescribing, ${ }^{14}$ despite a lack of evidence for their long-term safety and effectiveness. ${ }^{1}{ }^{15,16} \mathrm{~A}$ small proportion of people may experience effective pain relief from CNCP through opioid use if the dose can be kept low and daily use avoided. ${ }^{17.18}$ However, many patients stop using opioids long term because of adverse events or inadequate pain relief.' CNCP, defined as any painful condition lasting for $>3$ months not associated with a diagnosis of cancer, is estimated to affect $35.0 \%$ to $51.3 \%$ of adults in the UK. ${ }^{19}$ In the UK and internationally there is growing awareness of prescription opioid-related harms. . $^{13,20-27}$ Long-term use of prescription opioids in CNCP is associated with several adverse events ${ }^{28}$ including opioid analgesic dependence (OAD), addiction, and opioid-related death.2,29-35 For

JM Kesten, BSc, PhD, senior research associate in social science qualitative research, NIHR Collaboration for Leadership in Applied Health Research and Care (CLAHRC) West, University Hospitals Bristol NHS Foundation Trust; NIHR Health Protection Research Unit in Evaluation of Interventions, University of Bristol, Bristol. K Thomas, MSc, MSc (Res), PhD, FFPH, consultant senior lecturer in public health medicine, Population Health Sciences, Bristol Medical School, University of Bristol; South Gloucestershire Council, Bristol. LJ Scott, MSc senior research associate in quantitative applied health research; S Redwood, EdD, MA, RGN, RSCN, senior research fellow in ethnography, NIHR CLAHRC West, University Hospitals Bristo NHS Foundation Trust; Population Health Sciences, Bristol Medical School, University of Bristol, Bristol. K Bache, BSc, OAD coordinator, Developing Health and Independence, Bristol. M Hickman, MSc, PhD, professor in public health and epidemiology, Population Health Sciences, Bristol Medical School; NIHR Health Protection example, in 2017 there were 156 codeineand 185 tramadol-related deaths recorded in England and Wales. ${ }^{35}$ Variable prevalence rates of prescription opioid dependence have been reported. ${ }^{36-39}$ People dependent on prescription opioids are less likely to access traditional specialist substance misuse services than those dependent on illicit opioids, ${ }^{40}$ as they may not perceive themselves to be dependent, ${ }^{41}$ may be concerned about being labelled an 'addict' and the stigma associated with methadone use, ${ }^{42}$ and may not want to access the same services as 'addicts'. ${ }^{33}$ It is recommended that commissioners seek to provide separate services to treat prescription opioid dependence ${ }^{44}$ with strong collaboration between drug services and the patient's GP. ${ }^{45}$ There is currently no evidence for the efficacy or safety of interventions designed to reduce prescribed opioid use for CNCP. 46 Therefore, developing primary care-based interventions to reduce opioid dependence in patients with $\mathrm{CNCP}$ is a public health priority.

The aim of this research is to report the South Gloucestershire pain review service's

Research Unit in Evaluation of Interventions, University of Bristol, Bristol. R Campbell, MSc, PhD, FHEA, professor of public health research, Population Health Sciences, Bristol Medical School, University of Bristol, Bristol. AE Pickering. MBBS, PhD, FRCA, professor of neuroscience and anaesthesia, Department of Anaesthesia, University Hospitals Bristol NHS Foundation Trust; School of Physiology, Pharmacology and Neuroscience, University of Bristol, Bristol.

\section{Address for correspondence}

Sabi Redwood, NIHR CLAHRC West, Whitefriars, Lewins Mead, Bristol BS1 2NT, UK.

Email: sabi.redwoodabristol.ac.uk Submitted: 18 April 2019: Editor's response: 1 May 2019; final acceptance: 22 May 2019. CThe Authors

This is the full-length article (published online 8 Oct 2019) of an abridged version published in print. Cite this version as: Br J Gen Pract 2019; DOI: https://doi.org/10.3399/bjgp19X706097 


\section{How this fits in}

Primary care opioid prescribing to treat chronic non-cancer pain (CNCP) has progressively increased despite a lack of evidence for long-term safety and effectiveness. This mixed-methods study reports the acceptability of a new, primary care-based service, the South Gloucestershire pain review service, aimed at helping patients with CNCP on longterm opioid painkillers to explore their use of opioids, support non-pharmacological pain management strategies, and reduce their opioid dosage. This study found that the service was acceptable to service users and providers. The findings can be used to inform future service design highlighting the importance of the project worker and the value of running a flexible, individually tailored service.

acceptability, defined as the perceived appropriateness of an intervention. ${ }^{47}$ An evaluation of the service's potential impact on participants' health and wellbeing is presented elsewhere. ${ }^{48}$

\section{Pain and opioid use service}

The South Gloucestershire Council Public Health and Wellbeing Division commissioned the service for 2 years from September 2016 It was delivered in two GP practices that were selected for the presence of clinician expertise or interest in substance misuse. The providers were Developing Health and Independence (DHI), which offers services, including drug and alcohol treatment, to support disadvantaged and marginalised people, ${ }^{49}$ and Battle Against Tranquillisers

Figure 1. Intervention logic model. aPresented elsewhere.
(BAT), a service designed to reduce the harm caused by benzodiazepines, tranquillisers, and sleeping pills. ${ }^{50}$ The latter provider subsequently withdrew owing to a lack of patients with co-occurring opioid and benzodiazepine dependence.

Adult patients prescribed opioids for CNCP for $>3$ months (defined as long term) ${ }^{2}$ and receiving at least three prescriptions in that period were eligible to receive the service. Though the definition of 'long term' varies in the published literature, ${ }^{28}$ the researchers used $>3$ months as this time period has been used in the literature and reflects the lack of evidence for the long-term effectiveness of opioids for CNCP.111,17,28,51 Patients using illicit drugs only or receiving end-of-life care were ineligible. An opioid risk assessment tool (ORAT) was used to screen medical records and identify cohorts of potentially eligible patients. Project workers sent eligible patients invitation letters on behalf of the GP practice.

The service was informed by the sharedcare model, which is a partnership approach to care between specialists and GPs for those with drug misuse issues. The shared-care model is common in the delivery of treatment for illicit drug addiction. ${ }^{42}$ It includes the prescription of opioid substitution therapy (OST), used to reduce the use of illicit drugs, and psychosocial interventions. It has been shown to be effective in reducing mortality rates $^{52}$ and blood-borne virus transmission ${ }^{53}$ in this population. The evidence base for the treatment of dependence on prescribed opioids is weak and draws on the evidence for the treatment of heroin dependence..$^{42}$ For example, it is currently unknown whether people dependent on prescribed opioids respond to OST in the same way as those dependent on heroin. ${ }^{42}$ Furthermore, it is important to note that not all patients with CNCP on high doses of opioids will meet the definition of dependence; therefore, these individuals would not benefit from treatment such as OST. The service was also underpinned by patient-centred counselling and cognitive behavioural therapy principles, and aimed to promote partnership working between two project workers, GPs, and consultants in pain management and addiction psychiatry. Patient review meetings between service providers were planned approximately monthly.

Once enrolled, an assessment was used to co-produce a tailored pain management plan with patients involving non-medical pain management strategies, including pacing (breaking tasks into manageable units), encouragement of movement and strength-building exercises, following a pain management book, ${ }^{54}$ mindfulness 
and relaxation exercises, and goal setting (Figure 1). These strategies were provided either by project workers within sessions or through community-based services, akin to social prescribing. ${ }^{55}$ The sessions involved evidence-informed discussions supported by written and video resources on how pain and opioids work, and how changing thinking styles and improving mental health can improve pain symptoms. This education aimed to enable patients to understand their pain and assess whether their opioids were working. The service involved reviewing the opioid type and dose, and, as appropriate, discussing and supporting a reduction in opioids (de-scripting).

\section{METHOD}

A mixed-methods evaluation was performed between August 2017 and August 2018.

\section{Descriptive data}

This article presents data from 25 semistructured interviews (18 patients, 7 service providers) describing within-service and community interventions collected by project workers.

\section{Qualitative data}

A convenience sample from those patients who gave permission to be contacted were invited by telephone to take part in a oneto-one semi-structured interview either in person or by telephone. This was followed up by a patient information sheet further explaining the study. Interview participants provided written or audio-recorded verbal informed consent. Patients received GBP 10 shopping vouchers to thank them for their time.

Patient interview topic guides explored experiences of the service, including what worked well and what could be improved. Patient age, sex, previous pain clinic use, and pain medication were recorded.

Interviews with service providers (lead GPs, any GPs involved in the service, the project workers, and the service delivery manager) explored views on the service and partnership working. GP practices were reimbursed GBP 40 per 30-minute interview for the GPs' time.

The interviews captured several acceptability constructs: 47 'affective attitude' (feelings towards the service); 'burden' (effort required to participate); "intervention coherence' lunderstanding of the intervention and how it works); 'perceived effectiveness' lextent to which intervention is perceived to achieve its goal); and 'selfefficacy' to perform intervention behaviours.
Data collection ended when enough information to explore perceptions of the service had been obtained. This decision was informed by the 'information power' concept, meaning, the greater the information provided by participants, the smaller the sample required. ${ }^{56}$ Issues informing information power include: the breadth of the study aim, that is, broader aims require a larger sample as the phenomenon covered is more comprehensive; characteristics of the participants, that is, a sample with rich experiences relevant to the research can be smaller than one with less relevant experiences; depth and quality of data, that is, focused and clear data require a smaller sample; and the analysis approach, in other words, an exploratory analysis requires a larger sample than a more focused approach. ${ }^{56}$

\section{Analysis}

Qualitative analysis began shortly after data collection and informed changes to the topic guides. Inductive thematic analysis ${ }^{57}$ was performed using QSR NVivo (version 10). ${ }^{58}$

\section{RESULTS}

Of 34 patients, 22 (65\%) consented to be contacted about an interview. Two declined to be contacted lone had too many things to cope with' and one was 'too ill') and one was not invited because of mental health problems. Nine were not asked for permission to be contacted as data collection had finished. Two patients who agreed to be contacted were not invited as adequate data had been collected to understand experiences of the service. ${ }^{56}$ In total, 20 patients were invited to participate, of whom 18 agreed and two did not respond, giving a $90 \%$ recruitment rate. Participant characteristics are presented in Table 1 and details of the entire cohort are available from the authors on request.

Seven service providers $(n=2$ project workers, $n=1$ service delivery manager, $n=4$ GPs) were interviewed. An addiction specialist and consultant psychiatrist did not respond to interview invitations.

\section{Experiences of the new service}

Enrolment into the service. The ORAT tool was found difficult to use and insensitive, generating large numbers of records for the project workers to screen and discuss with GPs. Instead, GPs' direct referrals were regarded as more efficient.

The invitation process was acceptable to most patients as referral was experienced as informal, quick, and easy. Most patients described receiving clear invitations 
Table 1. Interview participant characteristics, $N=18$

\begin{tabular}{|c|c|}
\hline Characteristics & $\begin{array}{c}\text { Interviewed service } \\
\text { users } n(\%)^{\mathrm{a}}\end{array}$ \\
\hline Female & $12(66.7)$ \\
\hline Mean age, years (SD) & $52.8(9.8)$ \\
\hline \multicolumn{2}{|l|}{ Employment status } \\
\hline Unemployed/retired & 15 (83.3) \\
\hline Employed & 3 (16.7) \\
\hline \multicolumn{2}{|l|}{ Living with anyone } \\
\hline Yes & $12(66.7)$ \\
\hline No & 6 (33.3) \\
\hline \multicolumn{2}{|l|}{ GP practice } \\
\hline Practice 1 & $9(50.0)$ \\
\hline Practice 2 & $9(50.0)$ \\
\hline \multicolumn{2}{|l|}{ Mental health issues (diagnosed or undiagnosed) } \\
\hline Yes & $11(61.1)$ \\
\hline Depression & $10(-)$ \\
\hline Anxiety & $2(-)$ \\
\hline Bipolar tendencies & $1(-)$ \\
\hline No & $7(38.9)$ \\
\hline \multicolumn{2}{|l|}{ Previous attendance at pain clinic } \\
\hline Yes & 15 (83.3) \\
\hline No & $3(16.7)$ \\
\hline \multicolumn{2}{|l|}{ Description of pain ${ }^{b}$} \\
\hline Arthritis/osteoarthritis & $9(50.0)$ \\
\hline Generalised and localised joint and muscular pain & $9(50.0)$ \\
\hline Crohn's disease & $1(5.6)$ \\
\hline \multicolumn{2}{|l|}{ Opioid drug ${ }^{b}$} \\
\hline Buprenorphine & $4(22.2)$ \\
\hline Codeine family & $11(61.1)$ \\
\hline Morphine & $9(50.0)$ \\
\hline Oxycodone family & $7(38.9)$ \\
\hline Tramadol & $4(22.2)$ \\
\hline \multicolumn{2}{|l|}{ Baseline medication (excluding opioids) } \\
\hline Benzodiazepines & $5(27.8)$ \\
\hline SSRI antidepressants & $1(5.6)$ \\
\hline Other antidepressants & $1(5.6)$ \\
\hline Amitriptyline & $3(16.7)$ \\
\hline Gabapentin & $3(16.7)$ \\
\hline Pregabalin & $1(5.6)$ \\
\hline Other & $18(100.0)$ \\
\hline \multicolumn{2}{|c|}{$\begin{array}{l}\text { a Unless described otherwise. }{ }^{b} \text { Patients taking more than one class of opioid or baseline medication contribute } \\
\text { a count to each class of drug they take, therefore percentages do not add up to } 100 \% . S D=\text { standard deviation. } \\
\text { SSRI = selective serotonin reuptake inhibitors. }\end{array}$} \\
\hline
\end{tabular}

from GPs during consultations and via letters. GP endorsement enhanced the perceived trustworthiness of the service and encouraged participation. In contrast, one patient negatively experienced a verbal invitation from their GP as the GP implied the intention was to stop their opioid prescription. Another reacted negatively to the mention of the organisation, BAT, in the invitation materials:

'It [invitation letter] said it was called BAT, Battling Against Tranquillisers ... that did sort of really upset me because / think battling against tranquillisers is someone who's using them as an addictive thing and I wasn't using them because I was addicted. I was using them to combat pain so I could continue a semi-normal life. ... The doctors have been readily giving out these prescriptions, so if anyone's battling against tranquillisers it's the doctors. '(Patient [P], interview [I] 21)

Assessment process and pain management plan development. Project workers described the assessment process as building a relationship with patients, enabling them to understand their lives and identify issues affecting them and their pain. Most patients found the assessment process acceptable:

'Straight from the off he [project worker] is not sort of judging you if you know what I mean? He's sort of understanding what's going on and ... some of the things he said then made sense to me.' $(P, 18)$

Within-session components. Project workers used a range of strategies including encouraging pacing, physical exercises, following a pain management book, mindfulness and relaxation exercises, and goal setting. The proportion of all patients (not only those interviewed) receiving each within-session intervention (Figure 2) was as follows: pain management book (74\%), OAD worksheets (71\%), de-scripting (62\%), exercise planning (53\%), and sleep hygiene $(50 \%)$.

\section{Pain management strategies}

Patients learnt about pacing and strategies for avoiding the 'over-activity trap': the perceived need to complete many tasks on 'good pain days' that contribute to subsequent 'bad pain days':

'First of all, it was just sort of talking and then it was coping strategies, pacing - I'm not good at pacing - if I have a good day... I try and get everything done and am then knocked out for a couple of days but now I've learnt to I'll perhaps iron a couple of things and then I'll sit down rather than stand there and do the whole lot. ' $(\mathrm{P}, \mathrm{I1})$

Several patients described the pain management book and accompanying relaxation $C D$ as helpful, informative, and relatable. A small number described using the book to help formulate goals as well as using it outside of sessions. However, others described difficulties concentrating 


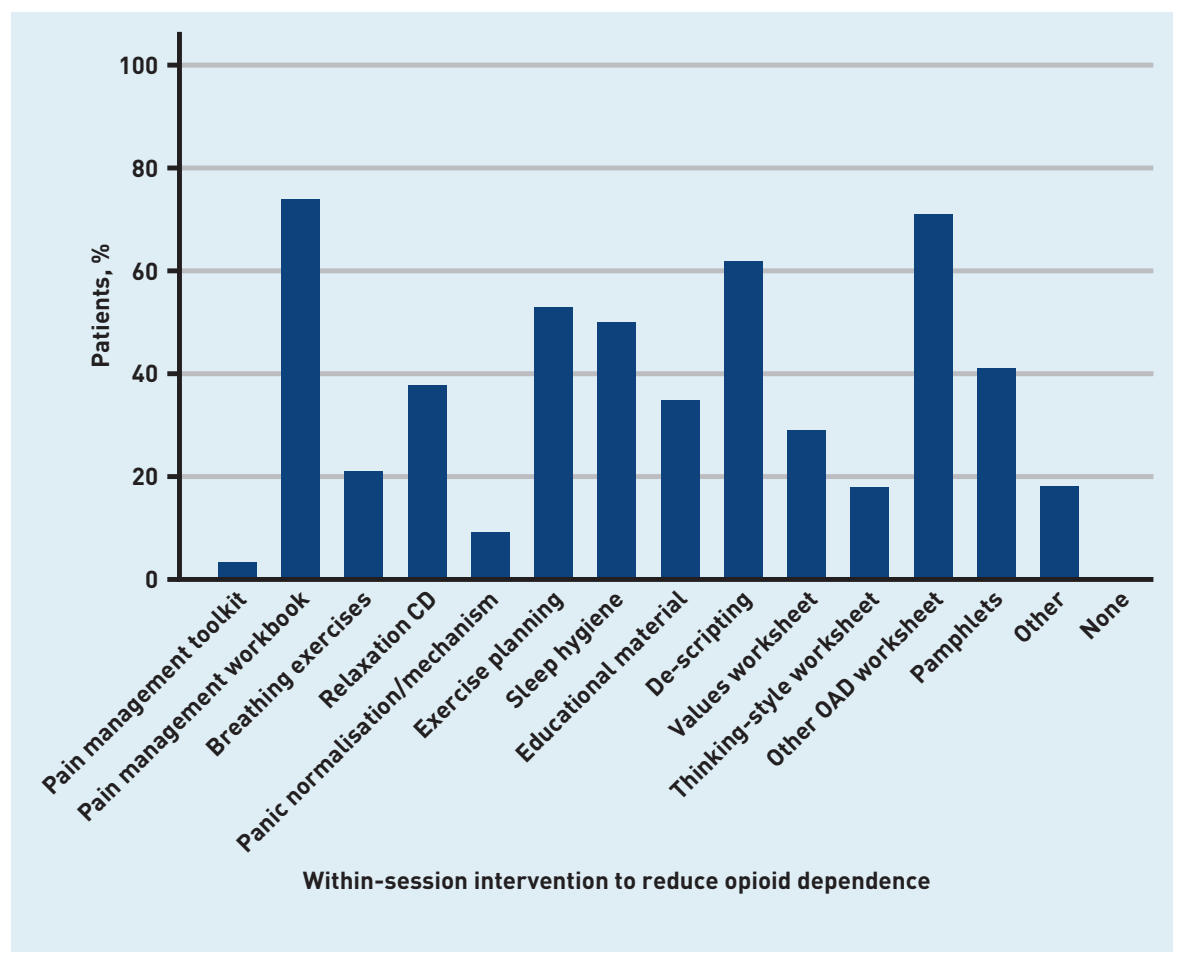

Figure 2. Proportion of patients accessing withinsession components.

$O A D=$ opioid analgesic dependence.

Figure 3. Proportion of patients accessing communitybased services and social prescribing. $O A D=$ opioid analgesic dependence. on the book, and some parts were said to be irrelevant and to oversimplify CNCP.

and the little books were brilliant because you do feel that you're on your own, that nobody else sort of understands, and my husband's read it, and ... you think, "Oh yeah, that's me, that's me", so yeah, it was really interesting.' $(P, 112)$

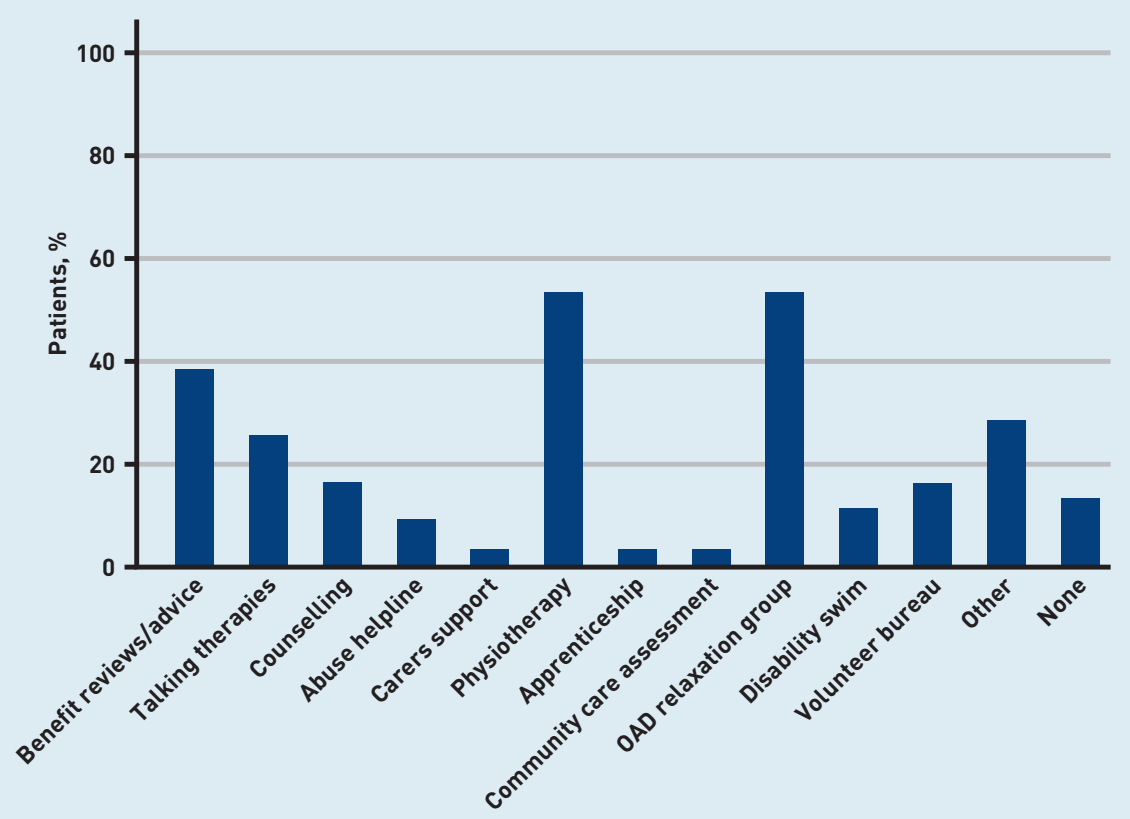

Community-based services and social prescribing to reduce opioid dependence

I got sort of irritated by [the book] and ... I tried my best to sort of have an open mind with it but I just really didn't like it. It's very rigid as well and you know, well I found it rigid.' $(P, 19)$

Opioid review and changes. Some patients were keen to conduct a review of their medication and to reduce their dose or change the type of opioid, driven by a recognition that they were on a high dose, or wanted to reduce the side effects from their medication. Overall, GPs facilitating changes to prescriptions worked smoothly, though time delays were experienced by some. A small number of patients had reservations about reducing their dose at home, rather than as a hospital in-patient, because of fears about withdrawal symptoms:

We would talk for quite a long time about the withdrawal and in the beginning, I was really scared and I said "Well, there's no way I am doing it unless you can send me to somewhere where I can actually live in and sort of you know?" But, we sort of discussed that and then I sort of thought "Well, no, I think I can do it with his help and support." $(P, 19)$

Community-based services. The highest proportion of patients selected physiotherapy services and participation in a relaxation group (53\% respectively) (Figure 3). Other community-based social prescribing services focused on: quality of life; social interaction and self-esteem through voluntary work; applying for an assistance dog; a 'Men in Sheds' project Icommunity spaces for men to connect to help reduce loneliness and isolation); physical activity, for example, gym sessions; and financial advice and support, for example, personal independence payment claim support and working rights advice:

He really helped me with that [applying for an assistance dog] because again, with my confidence I was reluctant to sort of ring them up ... and he was like "No, you do it" and / did. ' $(\mathrm{P}$, 19)

Three patients talked about appreciating funding to access community services. A small number of patients and project workers described delays accessing some services, owing to long waiting lists.

The project workers and some patients described enjoying the relaxation group, finding it helpful and valuing connecting with others in a similar situation. Group attendance was variable, and two patients 
were unable to attend because the group ran during the working day. A small number of patients were intimidated by the group format and did not feel confident to attend:

At first, I hated the breathing ... I think a lot of that was to do with my confidence as well because I felt very self-conscious in the group, breathing with other people, and I think a few people probably felt it but I vocalised it and they were all really supportive ... but when I came home, obviously what I learnt there, I was able to practise here and I felt more comfortable. '(P, 19)

\section{Service approach}

Patient-centred counselling. Session day, time, frequency, content, pace, and location were selected and modified to suit patient needs. Service duration was also more open ended than previous services, running for a maximum of 2 years. Patients liked this approach because it was more person centred than other services and reduced the pressure on them to make lifestyle or medication dose changes within a set timeframe. A few patients talked about their partners, parents, or carers attending some or all sessions that offered them insights into what the patient was experiencing, enabling them to support the patients, and helped the patient recall what had been discussed.

Patients appreciated that the service was not like the traditional medical model or mental health and pain management services. All interviewee groups reported that patients valued having time to discuss their pain and its management with someone who could spend time listening to them. Patients and providers acknowledged that GPs do not have time to discuss pain management or reduction in medication in detail, owing to limited appointment times:

It was one-on-one as well and it wasn't rushed. If you had something to say he would just sit there or advise or listen. (P, I21)

Relationships and communication. Project workers and GPs described the importance of forming a trusting relationship with patients in supporting openness during the sessions, and willingness to try suggested strategies. Patients described the project workers as encouraging, motivating, kind, and good listeners. They provided advice and supported them to implement changes related to pain management in a gentle way. The continuity of the project worker was experienced positively. Communicating confidentially with someone who was nonjudgemental, understood the physiology and psychology of pain, empathised with their experience, and was outside of the immediate family or caring network was welcomed:

I'm enjoying the fact that I've got somebody outside of my immediate family that I can just chat to that understands what I'm going through and can sort of guide me, you know, as to how to move forward and try and avoid painful flare-ups. '(P, 114)

Project workers consulted with GPs about opioid reductions and changes to patient medication, and kept GPs updated about the sessions through written notes on patient records and an internal messaging system. Most GPs felt this method of communication worked well, and project worker liaison with GPs was viewed positively by most patients. Project workers who were based in the GP practice facilitated informal conversations with GPs. Two patients commented on the sense of safety and reassurance that GP involvement provided for them:

Within EMIS [patient administration system] you can send tasks to users and so he [project worker] can send a task about a specific patient, saying l've seen him today. Certainly, when he starts dose reduction, he'll tell you what he's doing, and he'll put the plan on the record. It's helpful to have a summary of what he's doing with people. (GP, I20)

A small number of patients experienced communication problems with the GP or project worker. For example, one patient was refused appointments with their GP as they were under the care of the project worker. Instead, the GP and project worker discussed the patient's care without them. This patient disliked not being present for these conversations and having access to the GP restricted. Other patients also wanted more support from the GP during the service, especially when reducing opioids, for example, one patient felt more clinical expertise and general support from a GP was needed:

I think it is important if you're reducing that you are, I mean not to get special treatment, but you are able to have access to a doctor, even if it's just a phone call to say, you know, can you help me. '(P, 19)

One GP described supporting patients when they were reducing their opioids through phone calls and house visits. The lead GPs described struggling to allocate 
time to support the project workers as their time was unfunded. A lack of clinical supervision left the project workers feeling inadequately supported at times.

Scheduling multidisciplinary meetings between GPs, project workers, and addiction or pain specialists was difficult, and the involvement of the psychiatrist and pain specialist consultant was less than anticipated. The project workers were disappointed by this and felt that delayed responses from specialists negatively affected the patients' confidence in their knowledge and ability to support them.

Focus on wellbeing and mental health. All participant groups described the service as supportive of improvements in patient wellbeing and providing support for complex social and psychological issues, including social isolation, bereavement, problems related to family life, finances and employment, histories of trauma and abuse, low self-esteem and confidence, anxiety, and depression. Such issues had become intrinsically linked to CNCP either as a cause, contributor, or consequence. Project workers described trying to address patients' negative self-image by encouraging self-kindness.

Project workers observed that opioids were used by some people for reasons other than pain management, such as sedation and management of psychological symptoms:

For some people if you track over a week how they're taking it, then you can kind of see patterns that don't correspond with pain spikes. So, people are using it for something else and there've been a couple of "aha" moments with clients where they've gone "oh right, yes it goes up when my horrible father comes and gives me [hell]" and someone going "yes, I sedate myself". (Project worker 1, 113)

A self-assessment worksheet helped patients identify patterns of opioid use coinciding with stressful periods rather than pain spikes, thus increasing self-awareness of the link between wellbeing and pain. A negative unintended consequence of discussing the relationship between the mind and pain was for a small number of patients to think the project worker was implying their pain was not 'real':

In the research [there is a] huge overlap between kind of your emotional state and the amount of pain you feel. Also, around your ability to kind of tolerate the frustrations of pain. If you're not in a good space, you're not gonna be able to do that. If you're not in a good space, the chances are you're gonna be at home. If you're at home you're not working, you're not going to feel good about yourself. If you're not kind of working your body's gonna start moving less so there's this ... horrible ... downward spiral.'(Project worker 1, 113)

Two patients thought the pace of moving onto certain aspects, such as looking at their hobbies or starting to consider reducing their medication, would be discussed earlier on, but they acknowledged the need to address other mental health-related issues first to ensure they were ready. Indeed, setting goals was described by a small number of patients and Project worker 2 as challenging because of psychological readiness, emotional state, and general struggle to commit to setting goals.

For example, confronting troubling issues including past trauma was difficult for some:

In the early days I did find it quite difficult because when you're talking about your pain and your lifestyle, it's just highlighting how bad you feel.' (P, I2)

\section{Factors to consider for service} development

Most GPs and patients made no critical comments about the service and nine patients wanted the service to be kept the same in future. Keeping the service person centred and not prescriptive was viewed as important. Maintaining a longterm approach was desired by patients and project workers as CNCP is a complex issue that takes time to address, and requires a trusting relationship with the project worker.

There was agreement among the GPs and project workers that identifying eligible patients using clinician knowledge rather than software should continue. To enhance its effectiveness, two GPs proposed that the service could target patients who have expressed concern about their opioid use and motivation to change. GPs also commented that this type of service could be used to support patients from the onset of a pain condition to prevent long-term opioid use. Indeed, two patients talked about being unaware of their medication's addictive properties when first prescribed.

The project worker-patient relationship was perceived to be crucial for ensuring the success of any future service. However, the importance of commissioning a service rather than employing individual project workers was recognised. Both project 
workers warned against running the service with high numbers of patients and short appointment times, as this would undermine the ability to form a therapeutic relationship.

GPs highlighted the need for funding to support their involvement in future. Similarly, continuing a budget for each patient was recommended.

All participant groups agreed that running the service within GP practices was important in terms of access, communication, and familiarity. Additionally, one project worker felt the service could be embedded within the pain management pathway offering services within the community either before or after engagement with pain management clinics.

\section{DISCUSSION}

\section{Summary}

The enrolment process, open-ended, person-centred, primary care-based delivery and content focusing on psychological issues underlying CNCP, were acceptable elements of the South Gloucestershire pain review service. Patients welcomed having time to discuss their pain, its management, and related psychological issues with a consistent and supportive project worker The service has also been found to be feasible in relation to recruitment, attendance, and ability to measure outcomes. ${ }^{48}$

\section{Strengths and limitations}

Interviews were conducted with a diverse range of patients and providers, allowing triangulation of experiences and enhancing the findings' credibility. Using qualitative methods facilitated an in-depth exploration of the acceptability of the service. .9,60 $^{2}$

The patients' close relationship with the project workers may have resulted in reluctance to provide critical comments. However, the findings reflect a range of positive and negative views, suggesting the risk of this was minimal.

The GP practices were selected for the presence of clinician expertise in substance misuse. Therefore, it is unclear whether the service would be acceptable or successful elsewhere.

\section{Comparison with existing literature}

There is a dearth of evidence, including trials, on the efficacy or safety of interventions designed to reduce dependence on opioids prescribed for CNCP. ${ }^{46}$ Public Health England are currently reviewing the evidence for effective prevention and treatment of dependence, and withdrawal and discontinuation syndrome for prescribed medicines lincluding opioid pain medications). ${ }^{61}$ A self-management group intervention (COPERS) to help people cope with chronic musculoskeletal pain delivered over 3 days by trained facilitators, and an additional session after 2 weeks, was not effective in reducing pain-related disability at 12 months, though benefits were observed at 12 months for depression and social integration. ${ }^{62}$ The findings from the current service suggest that prolonged engagement helps enhance service acceptability, which in turn could support improved outcomes. The I-WOTCH IImproving the Wellbeing of People with Opioid Treated Chronic Pain) trial is currently examining the effectiveness of the COPERS intervention combined with individual support for people using strong opioids for CNCP.63 The presented study highlights the importance of such individually tailored support.

The need to address this problem using a multidisciplinary, personalised approach, focused on alternative pain management strategies and addressing psychological issues underlying pain, is recognised. ${ }^{\text {40,64-66 }}$ This pilot study is similar to other social prescribing initiatives highlighting benefits and challenges of collaborative working and issues of insufficient capacity and funding. ${ }^{67}$

Primary care is believed to be an ideal place for managing patients with prescription opioid dependence. ${ }^{65,68}$ Furthermore, GPs are generally supportive of the recommendation to provide separate services for the treatment of prescription opioid dependence, and recognise that they have an important role to play in identifying and treating these patients. ${ }^{38}$ Efforts to improve prescribing appropriateness have been called for. ${ }^{14} \mathrm{~A} G \mathrm{GP}$ training component was originally planned as part of the service. However, due to a lack of appropriate expertise, this component could not be delivered, and therefore the acceptability and perceived value of this is an area for further research.

\section{Implications for research and practice}

This service model may be a useful means to manage patients with CNCP using prescribed opioids long term. The findings can be used to inform future service design, highlighting the importance of the project worker and the value of running a flexible, individually tailored service incorporating social prescribing. In the future, funding would be needed to ensure GPs have dedicated time to support a similar service, and to ensure that project workers receive adequate clinical supervision. A randomised controlled trial and economic evaluation are needed to formally test the effectiveness of the service. 


\section{REFERENCES}

1. Noble M, Treadwell JR, Tregear SJ, et al. Long-term opioid management for chronic noncancer pain. Cochrane Database Syst Rev 2010; (1): CD006605. DOI https://doi.org/10.1002/14651858.CD006605.pub2.

2. Chou R, Turner JA, Devine EB, et al. The effectiveness and risks of long-term opioid therapy for chronic pain: a systematic review for a National Institutes of Health Pathways to Prevention workshop. Ann Intern Med 2015; 162(4): 276-286.

3. Foy R, Leaman B, McCrorie C, et al. Prescribed opioids in primary care: cross-sectional and longitudinal analyses of influence of patient and practice characteristics. BMJ Open 2016; 6(5): e010276.

4. Mordecai L, Reynolds C, Donaldson LJ, de C Williams AC. Patterns of regional variation of opioid prescribing in primary care in England: a retrospective observational study. Br J Gen Pract 2018; DOI: https://doi.org/10.3399/ bjgp18X695057.

5. Zerzan JT, Morden NE, Soumerai S, et al. Trends and geographic variation of opiate medication use in state Medicaid fee-for-service programs, 1996 to 2002 Med Care 2006; 44(11): 1005-1010.

6. Leong M, Murnion B, Haber PS. Examination of opioid prescribing in Australia from 1992 to 2007. Intern Med J 2009; 39(10): 676-681.

7. Fischer B, Jones W, Krahn M, Rehm J. Differences and over-time changes in levels of prescription opioid analgesic dispensing from retail pharmacies in Canada, 2005-2010. Pharmacoepidemiol Drug Saf2011; 20(12): 1269-1277.

8. Zin CS, Chen LC, Knaggs RD. Changes in trends and pattern of strong opioid prescribing in primary care. Eur J Pain 2014; 18(9): 1343-1351.

9. Ruscitto A, Smith BH, Guthrie B. Changes in opioid and other analgesic use 1995-2010: repeated cross-sectional analysis of dispensed prescribing for a large geographical population in Scotland. Eur J Pain 2015; 19(1): 59-66.

10. Bedson J, Chen Y, Hayward RA, et al. Trends in long-term opioid prescribing in primary care patients with musculoskeletal conditions: an observational database study. Pain 2016; 157(7): 1525-1531. DOI: https://doi.org/10.1097/j. pain. 0000000000000557 .

11. Stannard C, Coupe M, Pickering T. Opioids in non-cancer pain. Oxford: Oxford University Press, 2013

12. Fain KM, Alexander GC. Mind the gap: understanding the effects of pharmaceutical direct-to-consumer advertising. Med Care 2014; 52(4): 291 293. DOI: https://doi.org/10.1097/MLR.0000000000000126.

13. Stannard C. Opioids in the UK: what's the problem? BMJ 2013; 347: f5108.

14. Curtis HJ, Croker R, Walker AJ, et al. Opioid prescribing trends and geographical variation in England, 1998-2018: a retrospective database study. Lancet Psychiatry 2019; 6(2): 140-150. DOI: https://doi.org/10.1016/S2215 0366(18)30471-1.

15. Franklin GM. Opioids for chronic noncancer pain: a position paper of the American Academy of Neurology. Neurology 2014; 83(14): 1277-1284. DOI: https://doi.org/10.1212/WNL.0000000000000839.

16. Els C, Jackson TD, Hagtvedt R, et al. High-dose opioids for chronic non-cancer pain: an overview of Cochrane Reviews. Cochrane Database Syst Rev 2017; (10): CD012299. DOI: https://doi.org/10.1002/14651858.CD012299.pub2.

17. National Institute for Health and Care Excellence. Medicines optimisation in chronic pain. KTT21. London: NICE, 2017. https://umw.nice.org.uk/advice/ktt21/ chapter/Evidence-context\#managing-chronic-pain laccessed 13 Sep 2019).

18. Faculty of Pain Medicine. Opioids aware: a resource for patients and healthcare professionals to support prescribing of opioid medicines for pain. 2019. https:// uww.rcoa.ac.uk/faculty-of-pain-medicine/opioids-aware laccessed 3 Sep 2019).

19. Fayaz A, Croft P, Langford RM, et al. Prevalence of chronic pain in the UK: a systematic review and meta-analysis of population studies. BMJ Open 2016; 6(6): e010364

20. Giraudon I, Lowitz K, Dargan PI, et al. Prescription opioid abuse in the UK. Br J Clin Pharmacol 2013; 76(5): 823-824.

21. Stannard C. Opioid prescribing in the UK: can we avert a public health disaster? Br J Pain 2012; 6(1): 7-8.

22. Dhalla IA, Persaud N, Juurlink DN. Facing up to the prescription opioid crisis. BMJ 2011; 343: d5142

23. BBC One. The doctor who gave up drugs: 'It's good pain'. 2016. https://www. bbc.co.uk/programmes/p047z3rp laccessed 3 Sep 2019).

24. BBC One. Panorama: hooked on painkillers. 2015. https://www.bbc.co.uk/ iplayer/episode/b06nzl6d/panorama-hooked-on-painkillers laccessed 3 Sep 2019).
25. Royal College of General Practitioners. RCGP substance misuse and associated health: prescription and over-the-counter medicines misuse and dependence. 2019. https://uww.rcgp.org.uk/-/media/Files/SMAH/RCGP-Factsheet-1_ artwork v3 28Apr.ashx?la=en laccessed 3 Sep 2019)

26. Mars SG, Bourgois P, Karandinos G, et al. 'Every "never" I ever said came true': transitions from opioid pills to heroin injecting. Int J Drug Policy 2014; 25(2): 257-266. DOI: https://doi.org/10.1016/j.drugpo.2013.10.004.

27. Birnbaum HG, White AG, Schiller $M$, et al. Societal costs of prescription opioid abuse, dependence, and misuse in the United States. Pain Med 2011; 12(4): 657-667. DOI: https://doi.org/10.1111/j.1526-4637.2011.01075.x.

28. Els C, Jackson TD, Kunyk D, et al. Adverse events associated with mediumand long-term use of opioids for chronic non-cancer pain: an overview of Cochrane Reviews. Cochrane Database Syst Rev 2017; (10): CD012509. DOI: 10.1002/14651858.CD012509.pub2.

29. Manchikanti L, Fellows B, Ailinani H, Pampati V. Therapeutic use, abuse, and nonmedical use of opioids: a ten-year perspective. Pain Physician 2010; 13(5): 401-435

30. Braden JB, Russo J, Fan MY, et al. Emergency department visits among recipients of chronic opioid therapy. Arch Intern Med 2010; 170(16): 1425-1432.

31. Bedson J, Chen Y, Haywood R, et al. Long-term opioid prescribing and the risk of adverse events in patients with musculoskeletal pain: a cohort study. Rheumatology 2016; 55(Suppl 1): i51. https://doi.org/10.1093/rheumatology/ kew117.004.

32. Office for National Statistics. Deaths related to drug poisoning in England and Wales, 2014 registrations. 2015. https://www.ons.gov.uk/ons/dcp171778_414574. pdf (accessed 3 Sep 2019).

33. Hawton $\mathrm{K}$, Bergen $\mathrm{H}$, Simkin S, et al. Effect of withdrawal of co-proxamol on prescribing and deaths from drug poisoning in England and Wales: time series analysis. BMJ 2009; 338: b2270

34. Rudd RA, Aleshire N, Zibbell JE, Gladden RM. Increases in drug and opioid overdose deaths - United States, 2000-2014. Am J Transplant 2016; 16(4): 1323-1327.

35. Office for National Statistics. Deaths related to drug poisoning in England and Wales: 2017 registrations. 2018. https://mww.ons.gov.uk/ peoplepopulationandcommunity/birthsdeathsandmarriages/deaths/bulletins/ deathsrelatedtodrugpoisoninginenglandandwales/2017registrations laccessed 3 Sep 2019).

36. Degenhardt L, Bruno R, Lintzeris N, et al. Agreement between definitions of pharmaceutical opioid use disorders and dependence in people taking opioids for chronic non-cancer pain (POINT): a cohort study. Lancet Psychiatry 2015; 2(4): 314-322.

37. Vowles KE, McEntee ML, Julnes PS, et al. Rates of opioid misuse, abuse, and addiction in chronic pain: a systematic review and data synthesis. Pain 2015; 156(4): 569-576

38. Shapiro H. Opioid painkiller dependency (OPD): an overview. A report written for the All-Party Parliamentary Group on Prescribed Medicine Dependency. 2015. https://uww.drugsandalcohol.ie/25398/1/Opioid_painkiller_dependency_ Sept_2015.pdf (accessed 3 Sep 2019).

39. Minozzi S, Amato L, Davoli M. Development of dependence following treatment with opioid analgesics for pain relief: a systematic review. Addiction 2013; 108(4): 688-698

40. NHS National Treatment Agency for Substance Misuse. Addiction to medicine: an investigation into the configuration and commissioning of treatment services to support those who develop problems with prescription-only or over-the-counter medicine. 2011. https://www.bl.uk/collection-items/addictionto-medicine-an-investigation-into-the-configuration-and-commissioningof-treatment-services-to-support-those-who-develop-problems-withprescriptiononly-or-overthecounter-medicine laccessed 3 Sep 2019).

41. British Pain Society. Pain and substance misuse: improving the patient experience. 2007. https://www.britishpainsociety.org/static/uploads/resources/ misuse_0307_v13_FINAL.pdf laccessed 3 Sep 2019).

42. Clinical Guidelines on Drug Misuse and Dependence Update 2017 Independent Expert Working Group. Drug misuse and dependence: UK quidelines on clinical management. 2017. https://www.gov.uk/government/publications/drug-misuseand-dependence-uk-guidelines-on-clinical-management laccessed 3 Sep 2019).

43. Larance B, Campbell G, Moore T, et al. Concerns and help-seeking among patients using opioids for management of chronic noncancer pain. Pain Med 2019; 20(4): 758-769. 
44. Public Health England. Commissioning treatment for dependence on prescription and over-the-counter medicines: a guide for NHS and local authority commissioners. 2013. https://webarchive. nationalarchives.gov.uk/20170807160633/http://www.nta.nhs.uk/uploads/ pheatmcommissioningguide.pdf (accessed 3 Sep 2019).

45. Faculty of Pain Medicine. Patients with substance misuse: chronic pain management. 2019. https://www.rcoa.ac.uk/faculty-of-pain-medicine/opioidsaware/opioids-and-addiction/chronic-pain-management laccessed 3 Sep 2019).

46. Windmill J, Fisher E, Eccleston C, et al. Interventions for the reduction of prescribed opioid use in chronic non-cancer pain. Cochrane Database Syst Rev 2013; (9): CD010323. DOI: https://doi.org/10.1002/14651858.CD010323.pub2.

47. Sekhon M, Cartwright M, Francis JJ. Acceptability of healthcare interventions: an overview of reviews and development of a theoretical framework. BMC Health Serv Res 2017; 17(1): 88.

48. Scott LJ, Kesten JM, Bache K, et al. Evaluation of a primary care-based opioid and pain review service. Br J Gen Pract 2019; in press.

49. Developing Health and Independence. About us. https://uww.dhi-online.org.uk/ about-us laccessed 3 Sep 2019).

50. Battle Against Tranqulisers (BAT). About BAT. https://bataid.org/about-bat laccessed 3 Sep 2019).

51. Faculty of Pain Medicine. The effectiveness of opioids for long term pain. 2019. https://www.rcoa.ac.uk/faculty-of-pain-medicine/opioids-aware/clinical-use-ofopioids/effectiveness-for-long-term-pain laccessed 3 Sep 2019).

52. Hickman M, Steer $C$, Tilling $K$, et al. The impact of buprenorphine and methadone on mortality: a primary care cohort study in the United Kingdom. Addiction 2018; 113(8): 1461-1476.

53. Platt $L$, Minozzi S, Reed J, et al. Needle syringe programmes and opioid substitution therapy for preventing hepatitis $\mathrm{C}$ transmission in people who inject drugs. Cochrane Database Syst Rev 2017; (9): CD012021. DOI: https://doi. org/10.1002/14651858.CD012021.pub2.

54. Lewin R. Chronic pain. The pain management plan: how people living with pain found a better life; the things that helped them and the things that set them back. npowered, 2010.

55. King's Fund. What is social prescribing?2017. https://www.kingsfund.org.uk/ publications/social-prescribing laccessed 3 Sep 2019).

56. Malterud K, Siersma VD, Guassora AD. Sample size in qualitative interview studies: guided by information power. Qual Health Res 2016; 26(13): 1753-1760.

57. Braun V, Clarke V. Using thematic analysis in psychology. Qual Res Psychol 2006; 3(2): 77-101.
58. Boyatzis RE. Transforming qualitative information: thematic analysis and code development. Thousand Oaks, CA: Sage Publications, 1998.

59. O'Cathain A, Thomas KJ, Drabble SJ, et al. What can qualitative research do for randomised controlled trials? A systematic mapping review. BMJ Open 2013; 3(6): pii: e002889. DOI: https://doi.org/10.1136/bmjopen-2013-002889.

60. Yardley L, Morrison L, Bradbury K, Muller I. The person-based approach to intervention development: application to digital health-related behavior change interventions. J Med Internet Res 2015; 17(1): e30. DOI: https://doi.org/10.2196/ jmir.4055.

61. Public Health England. Scope of the prescribed medicines review. 2018. https:// wuw.gov.uk/government/publications/prescribed-medicines-review-scope/ scope-of-the-prescribed-medicines-review laccessed 3 Sep 2019).

62. Taylor SJ, Carnes D, Homer K, et al. Novel three-day, community-based, nonpharmacological group intervention for chronic musculoskeletal pain (COPERS): a randomised clinical trial. PLoS Med 2016; 13(6): e1002040. DOI: https://doi.org/10.1371/journal.pmed.1002040.

63. Warwick Clinical Trials Unit. I-WOTCH: improving the wellbeing of people with opioid treated chronic pain (I-WOTCH). 2017. https://warwick.ac.uk/fac/sci/med/ research/ctu/trials/iwotch/health laccessed 3 Sep 2019).

64. Brinksman S. Opioids and chronic pain in primary care. Br J Gen Pract 2018; DOI: https://doi.org/10.3399/bjgp18X698921.

65. Faculty of Pain Medicine. Identification and treatment of prescription opioid dependent patients. 2019. https://www.rcoa.ac.uk/faculty-of-pain-medicine/ opioids-aware/clinical-use-of-opioids/identification-and-treatment laccessed 3 Sep 2019).

66. Lagisetty P, Klasa K, Bush C, et al. Primary care models for treating opioid use disorders: what actually works? A systematic review. PLoS One 2017; 12(10): e0186315. DOI: https://doi.org/10.1371/journal.pone.0186315.

67. Skivington $\mathrm{K}$, Smith M, Chng NR, et al. Delivering a primary care-based social prescribing initiative: a qualitative study of the benefits and challenges. $\mathrm{Br} J \mathrm{Gen}$ Pract 2018; DOI: https://doi.org/10.3399/bjgp18X696617.

68. Leach JM. Managing addiction to prescribed opioids: the job of general practice? Br J Gen Pract 2018; DOI: https://doi.org/10.3399/bjgp18X698597. 